\title{
Chapter 5 \\ Potential of Low-Carbon Development in Vietnam, from Practices to Legal Framework
}

\author{
Nguyen Tung Lam
}

\begin{abstract}
Vietnam is not in the category of mandatory reductions of greenhouse gas emissions. However, when implementing the mitigation of greenhouse gas (GHG) emissions, Vietnam has many opportunities to access financial resources, technology and capacity building from developed countries to develop in a sustainable manner toward a green economy with low carbon and contribute to efforts to reduce global GHG emissions. Vietnam should prioritize the sectors for GHG reduction while ensuring the objectives of economic growth, employment, and economic development.

The GHG emissions in the energy and agriculture, forestry and land use (AFOLU) sectors are two of the greatest GHG emissions. Policies to reduce GHG emissions also have negative and unintended effects. Therefore analysis and evaluation of the externalities of policies and measures to reduce GHG emissions are essential. The negative externalities are considered as indirect costs of GHG emission reduction measures, therefore they are important when considering the priority of GHG emission reduction.

International experience of accessing low-carbon development programs from low-carbon development research is a valuable reference for Vietnam. The Asia Pacific Integrated Model (AIM model) to project GHG emission scenarios helps to identify priority sectors that have high potential in reducing GHG and less effects on the development targets. Accordingly, for developing countries like Vietnam, when the budget is not abundant and also to serve multiple objectives of other urgent development, GHG emission reductions in selected priority sectors and actionable measures need less investment and other negative impacts on socioeconomic development targets.

Research has contributed to the development of GHG emission reduction policies in Vietnam. It is considered as an important basis for construction, adjustment, and additional amendment of the legal system, mechanisms and policies to promote GHG emission reduction activities in industry and other sectors.
\end{abstract}

\footnotetext{
N.T. Lam $(\bowtie)$

Institute of Strategy, Policy on Natural Resources and Environment, Ministry of Natural

Resources and Environment, Vietnam, 479 Hoang Quoc Viet, Hanoi, Cau Giay, Vietnam e-mail: ntlam@isponre.gov.vn
} 
Keywords Vietnam • Low-carbon development • AIM model • GHG emission reduction - Mitigation

\section{Key Message to Policy Makers}

- In Vietnam, priority sectors should be identified to reduce investment for GHG reduction.

- Great potential exists in the energy, waste and AFOLU sectors in Vietnam.

- Both positive and negative effects of GHG emission reduction policies are identified.

\subsection{Introduction}

Low-carbon development considers reducing greenhouse gas emissions through reduced energy consumption by technological innovation and social attitudes. Some sectors have great potential to reduce carbon emissions such as energy, agriculture, industries, construction, and waste management. Recent research has shown that Vietnam has great potential to reduce GHG emissions in the energy sector or agriculture. However, to implement a low-carbon development strategy requires large financial capacity, high-tech capabilities and appropriate supporting policies. Besides, improper awareness about the benefits of implementing a low-carbon development strategy, for example, like expensive investment but no immediate economic returns, would be a challenge to successful low-carbon development implementation in Vietnam.

As a developing country, Vietnam has no obligation to reduce emissions in the present, but with implementation of the action program of voluntary reductions of GHG emissions, Vietnam has many opportunities to receive support from other developed countries to develop its economies toward low carbon, and also has an opportunity to contribute to global GHG emission reduction efforts. In a developing country like Vietnam, a policy to develop low carbon will benefit all aspects: reducing energy consumption, increasing energy efficiency, saving natural resources, technological modernization, increased levels of economic value added, and elimination of environmental pollution. This is an opportunity that Vietnam can take advantage of in the future.

Recognizing the importance of implementation of practical actions to respond to climate change, the Government of Vietnam has issued many related legal documents. From 2006 to 2010, the Government of Vietnam adopted many important policies such as the National Strategy for Environmental Protection, the National Target Program for Energy Saving and Efficiency, the National Target Program to Respond to Climate Change, the National Strategy for Solid Waste Management, the National Green Growth Strategy, etc., and promoted the economy toward low carbon. This is an important legal basis for the implementation of sustainable 
development policy in practice, toward a low-carbon economy in Vietnam. However, to effectively implement the policy, it requires the coordination and cooperation of many agencies and departments from the central to local levels. In particular, the successful experience throughout the world has demonstrated that policy measures toward strategic development of low carbon will provide practical effects if they are confirmed in terms of technology, trade, and economics; socially accepted; and put into a legal framework for implementation.

To be able to implement development toward low carbon effectively, it should be determined what areas of the economy will play a key role in cutting emissions, the level of reductions, and a roadmap of implementation reduction measures in selected economic sectors. The formulation and promulgation of a low-carbon development policy should also consider their potential impacts on the economy such as creating jobs, changes in national income, changing industry structure, economic scale investment requirements and necessary resources to carry out measures for each respective sector. In some countries around the world, especially in developed countries that have committed to the reduction of GHG emissions, growth toward low-carbon emissions is considered as an integral part of a national strategy on climate change. ${ }^{1}$ Thus quantitative research on low-carbon development arises as an essential need to provide a scientific basis for management decisions about the goals, schedule and reasonable solutions for strategic planning for economic development in the direction of decreasing GHG emissions. Recently, low-carbon development has received the attention of developing countries where the demand for fossil fuel has been increasing to meet the economic growth in the context of energy efficiency, which is still low. The study of low-carbon development has begun to be deployed in a number of countries with adjustments to suit their socio-economic conditions.

Although still relatively new in Vietnam, the recent problems of low-carbon development have received increasing attention of governments, international donors and agencies. In the implementation process of responsibility to participate in international exchange on climate change, the Ministry of Natural Resources and Environment has proposed to the Government policies and strategies for promoting low-carbon growth and a roadmap to reduce GHG emissions in Vietnam. The Prime Minister approved the National Green Growth Strategy, in which the economic development model toward low-carbon emissions is mentioned as important content of the strategy. ${ }^{2}$

In countries with emission reduction obligations, their policy will be anchored at the cutting rate that was committed to. Thus the trade-off between economic growth targets and the level of GHG emission reduction makes the cutting costs in

\footnotetext{
${ }^{1}$ Low-Emission Development Strategies (LEDS), Technical, Institutional and Policy Lessons. Clapp et al. OECD (2010). Available at http://www.oecd-ilibrary.org/environment/low-emis sion-development-strategies-leds_5k451mzrnt37-en?crawler $=$ true

${ }^{2}$ Decision 1393/QĐ-TTg dated 25/09/2012. "Chiến lược Tăng trưởng xanh quốc gia” (2012, in Vietnamese). Available at: http://vanban.chinhphu.vn/portal/page/portal/chinhphu/ hethongvanban?_page $=1 \&$ class_id=2\&document_id=163886\&mode $=$ detail
} 
developed countries very high. For Vietnam, the reduction of GHG emissions should be voluntary so it may optionally give GHG reduction targets. Thus the problem for Vietnam is not how great the trade-offs are but which reduction plans would be preferred alternatives. Identification of the objectives, contents and methods in each sector's cuts and the transformation roadmap to achieve the level of emission reductions cannot follow idealistic sentiments; they must be based on scientific methods of calculation taking into account the specific conditions of the national economic potential of the country, the context of international relations and the requirements of meeting the government's socio-economic development targets.

This paper presents an overview of the recent situation of GHG emissions in Vietnam, as well as a discussion on how the country should select priorities in selecting emission alternatives. It has four main parts; the first one introduces the context of socio-economic development in which GHG emission reduction has been considered as a commitment of the government to the international community for its contribution to the global GHG reduction efforts. The second part presents in detail the main GHG emissions from different sectors and their projections in the years to come. The next part looks at the priority in selecting the alternatives for GHG emissions that are required to help the country to be balanced with its socio-economic development targets. The final part focuses on the impacts of these reduction policies on the country's development with suggestions to reduce unintended effects.

\subsection{GHG Emissions in Vietnam}

\subsubsection{The Total Amount and Level of Greenhouse Gas Emissions in Vietnam}

Vietnam signed the United Nations Framework Convention on Climate Change (UNFCCC) in 1992 and ratified this Convention in 1994. Vietnam also signed the Kyoto Protocol (KP) in 1998 and officially approved it in 2002. Under the Kyoto Protocol, Vietnam is not in the group of countries that have a responsibility to reduce greenhouse gases.

Regarding actual GHG emissions, Vietnam is a country with low GHG emissions in the world. The emissions in 2000 were only about 150 million tons, out of 34,000 million tons of $\mathrm{CO}_{2}$ equivalent emissions worldwide (that is equivalent to approximately $0.44 \%$ ). However, it should be recognized that the emission rate per capita in Vietnam, although lower than those in China, Korea and Thailand, is growing faster than the rates in those nations. Specifically, emissions have increased by nearly 6 times, from 0.3 tons $\mathrm{CO}_{2} /$ person in 1990 to 1.71 tons $\mathrm{CO}_{2} /$ person in 2010, while China's emissions increased by 3 times, Korea's increased by 2.5 times and Thailand's increased by 2 times (Figs. 5.1 and 5.2). 
Fig. 5.1 GHG emissions per capita during the period of 1990-2010 (Source: Compiled from UN data at http://data.un.org/Data. aspx? $\mathrm{d}=$ MDG\& $\mathrm{f}=$ seriesRowID:751)
Fig. 5.2 The growing rate of GHG emissions per capita in Vietnam compared with some other countries (Source: http://data.un.org/ Data.aspx?d=MDG\& $\mathrm{f}=$ seriesRowID:751)
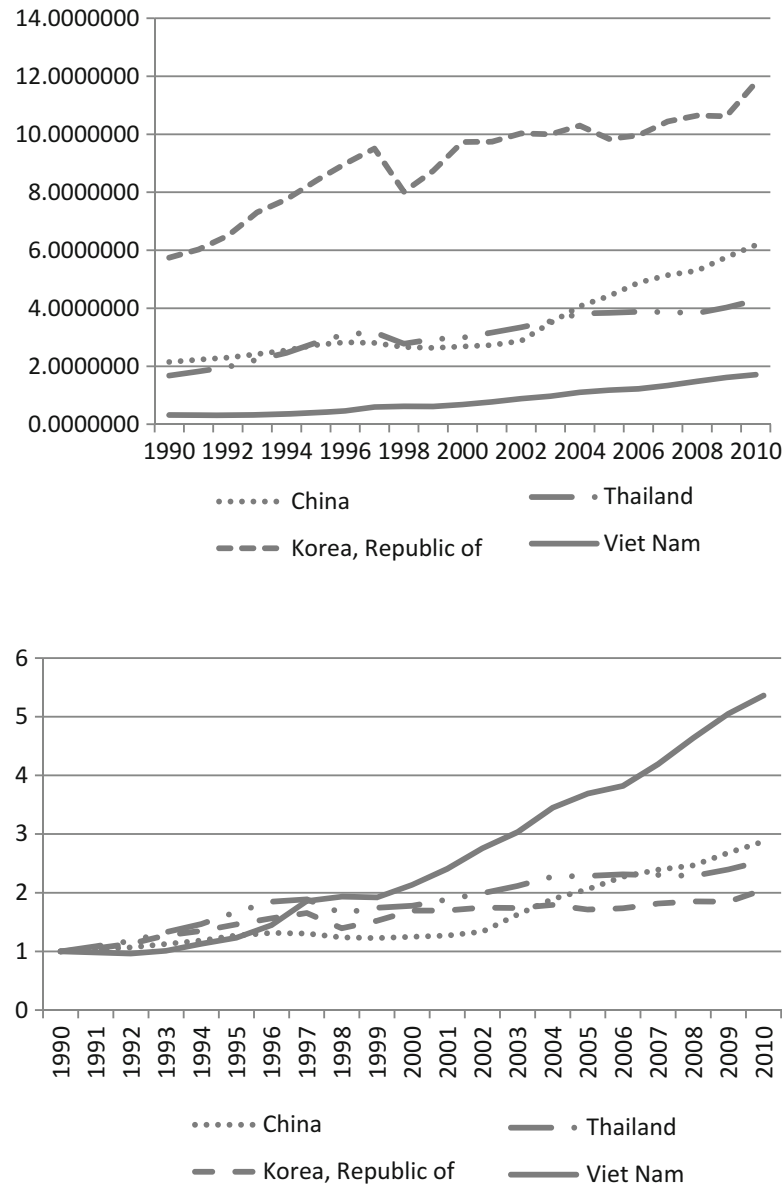

In the recent period (2001-2011), before the trend of economic development with a relatively high rate (average growth of 6-8\%), the increase in population led to the amount of Vietnam's greenhouse gases increasing. As expected, due to the economic development needs in the coming years, the amount of GHG emissions in Vietnam may be increased if there is not timely implementation of measures to reduce GHG emissions caused by economic development activities.

Vietnam conducted national GHG inventories for the years 1994, 2000 and 2005. This was to meet the country's commitments under the UNFCCC, also aiming to develop a database to support the formulation of policies related to climate change and greenhouse gases. The inventories therefore covered most sectors' GHG emissions in Vietnam.

All inventories were calculated using the Intergovernmental Panel on Climate Change (IPCC)'s 1996 guidelines for non-Annex I nations (Revised 1996 IPCC Guidelines for National Greenhouse Gas Inventories). The inventories for 2000 and 
Table 5.1 GHG inventories in Vietnam

\begin{tabular}{|c|c|c|c|c|c|c|}
\hline \multirow{2}{*}{$\begin{array}{l}\text { Year } \\
\text { Sector }\end{array}$} & \multicolumn{2}{|l|}{$1994^{a}$} & \multicolumn{2}{|l|}{$2000^{\mathrm{b}}$} & \multicolumn{2}{|l|}{$2005^{c}$} \\
\hline & $\mathrm{CO}_{2} \mathrm{t} / \mathrm{d}$ & $\%$ & $\mathrm{CO}_{2} \mathrm{t} / \mathrm{d}$ & $\%$ & $\mathrm{CO}_{2} \mathrm{t} / \mathrm{d}$ & $\%$ \\
\hline Energy & $25,637.09$ & 24.7 & $52,773.46$ & 35.0 & $101,934.90$ & 56.0 \\
\hline Industries & $3,807.19$ & 3.7 & $10,005.72$ & 6.6 & $14,590.82$ & 8.0 \\
\hline \multicolumn{7}{|l|}{ AFOLU } \\
\hline Agriculture & $52,450.00$ & 50.5 & $65,090.65$ & 43.1 & $83,828.40$ & 46.1 \\
\hline LULUCF & $19,380.00$ & 18.7 & $15,104.72$ & 10.0 & $-27,020$ & -14.8 \\
\hline Waste & $2,565.02$ & 2.4 & $7,925.18$ & 5.3 & $8,643.41$ & 4.7 \\
\hline Total & $103,839.30$ & 100.0 & $150,899.73$ & 100.0 & $181,977.53$ & 100.0 \\
\hline
\end{tabular}

Source: Compiled from Vietnam Second Communication Report, Ministry of Natural Resources and Environment (2010), and Interim Report of Inventory Capacity Building Project. JICA (2014)

${ }^{\mathrm{a} S e c o n d}$ Communication Report, MONRE 2010

${ }^{\mathrm{b}}$ Second Communication Report, MONRE 2010

' Interim Report of Inventory Capacity Building Project. JICA (as of 6/2014)

2005 were combined with the Good Practice Guidance versions from the IPCC for 2000 and 2003 in a number of areas.

The GHG inventory was conducted in economic sectors that have high emissions, including energy, industrial processes, agriculture, and land use-land use change-forestry (LULUCF), and waste sectors. GHG inventories cover three major categories including $\mathrm{CO}_{2}, \mathrm{CH}_{4}$ and $\mathrm{N}_{2} \mathrm{O}$.

\subsubsection{Structure and Trends in Greenhouse Gas Emissions in Vietnam}

A summary of the national GHG inventories in 1994, 2000 and 2005 is given in Table 5.1. The data in the table are the total amounts of GHG emissions in the base year and are converted into $\mathrm{CO}_{2}$ equivalents. Figure 5.3 shows the trends in GHG emissions from different sectors in the inventory periods.

Excluding the absorption from LULUCF, the volumes of GHG emissions from activities in the industrial, energy, agriculture and waste management sectors also tended to increase, but by different amounts. Among those, emissions from the energy sector have been the fastest rising trend. The change in the structure of GHG emissions as a result of the third inventory excluding the LULUCF sector is represented and trends are shown in Fig. 5.4.

\subsubsection{Trends in Emissions from Different Sectors}

Emissions from industrial processes and waste account for a small proportion of GHG emissions in Vietnam. With the economic development trend toward green 
Fig. 5.3 Total GHG emissions from different sectors in the inventory periods $\left(\times 1000 \mathrm{tCO}_{2} \mathrm{e}\right)$ (Source: Compiled from Vietnam Second Communication Report 2010, and Interim Report of Inventory Capacity Building Project. JICA 2014)

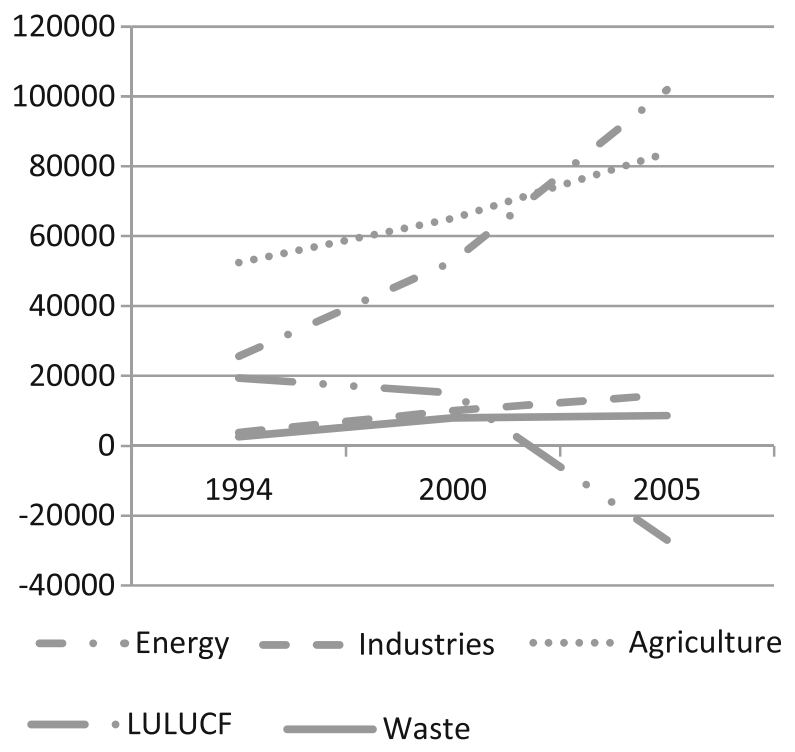

growth and low-carbon development, the industries that have high potential for emissions, such as cement, steel, and chemicals, will not likely be developed at high speed to create a larger proportion of the total emissions, while emissions from the waste sector will remain at the same level. Urban development will require accompanied waste minimization and management solutions will reduce the environmental pollution and GHG emissions.

The sectors that currently have the largest proportion of emissions are agriculture and energy. However, emissions from energy will tend to increase rapidly in the coming years in terms of total volume (Fig. 5.3) as well as the proportion of the emission structure (Fig. 5.4). As is likely in most other countries, the energy sector will account for the largest emissions in the economic structure of the country in the years to come.

In the previous year, emissions from the agricultural sector accounted for over $50 \%$ of the components of Vietnam's GHG emissions and emissions of $\mathrm{CO}_{2}$ and $\mathrm{CH}_{4}$ (mainly from the energy sector) accounted for approximately $50 \%$. However, the trend in emissions from energy will increase and serve as the main source of emissions in Vietnam in the coming years, and $\mathrm{CO}_{2}$ will be the main GHG emissions in Vietnam, beyond emissions of $\mathrm{CH}_{4}$ from agriculture and waste. 
Fig. 5.4 Trends in the proportions of GHG emissions from different sectors (Source: Vietnam Second Communication Report 2010, and Interim Report of Inventory Capacity Building Project. JICA 2014)

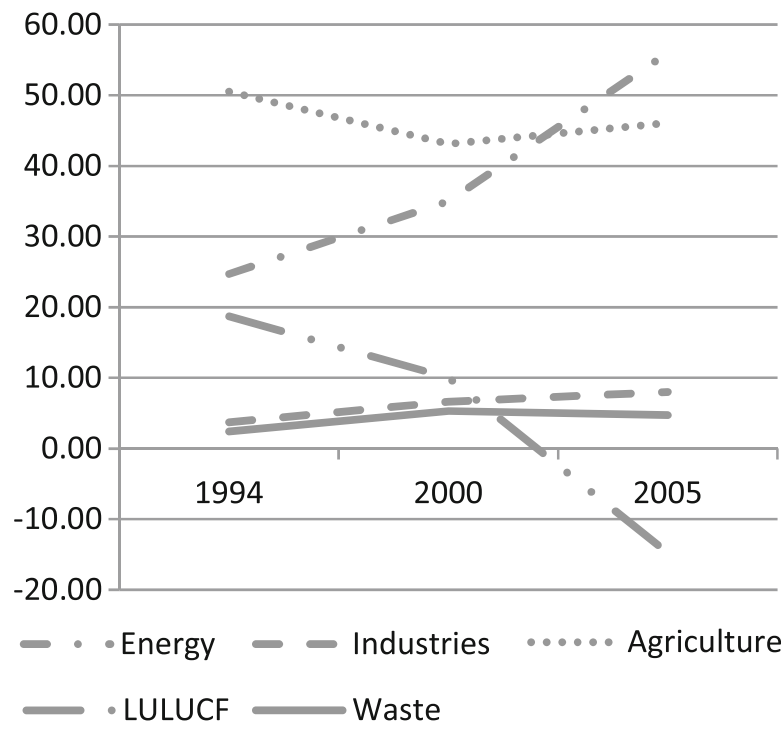

\subsubsection{Greenhouse Gas Emissions from Different Sectors}

\subsubsection{The Energy Sector}

The energy sector has had important implications for the process of sustainable development of the national economy and people's lives in recent years. Vietnam's energy sector has contributed significantly to the country's development, industrial growth and exports. The total primary energy consumption of Vietnam for the period of 2000-2009 showed an average increase of $6.54 \% / y e a r$ and reached 57 million toes (tons of oil equivalents). In 2009, the average coal consumption increased $12.12 \% / y e a r$, fuel $8.74 \%$ /year, gas $22.53 \% / y e a r$, and power $14.33 \%$ / year, reaching 74.23 billion $\mathrm{kWh}$.

The total final energy consumption in 2000 was 26.28 million toes, which increased to 40.75 million toes in 2007 , during which the proportion of coal consumption increased from 12.3 to $14.9 \%$, gasoline consumption increased from 26.3 to $34.4 \%$, gas consumption increased from 0.1 to $1.3 \%$ and electricity consumption increased from 7 to $12.9 \%$. Regarding the structure of energy consumption by different sectors, this has changed; in 2000, $30.6 \%$ of energy consumption was in industry, $14.7 \%$ was in transport, $1.5 \%$ was in agriculture, $48.8 \%$ was in the residential sector, and $4.4 \%$ was in commercial services. By 2007, the proportion in industry rose by $34.3 \%$, agriculture increased by $1.6 \%$, transportation increased by $21.2 \%$, the civil sector proportion dropped $39.1 \%$, and commercial services. ${ }^{3}$

\footnotetext{
${ }^{3}$ Vietnam Second Communication Report (2010), and Interim Report of Inventory Capacity Building Project. JICA (2014).
} 
Fig. 5.5 Total GHG emissions from the energy sector in the inventory periods $\left(\times 1000 \mathrm{tCO}_{2} \mathrm{e}\right)$ (Source: Vietnam Second Communication Report 2010, and Interim Report of Inventory Capacity Building Project. JICA 2014)

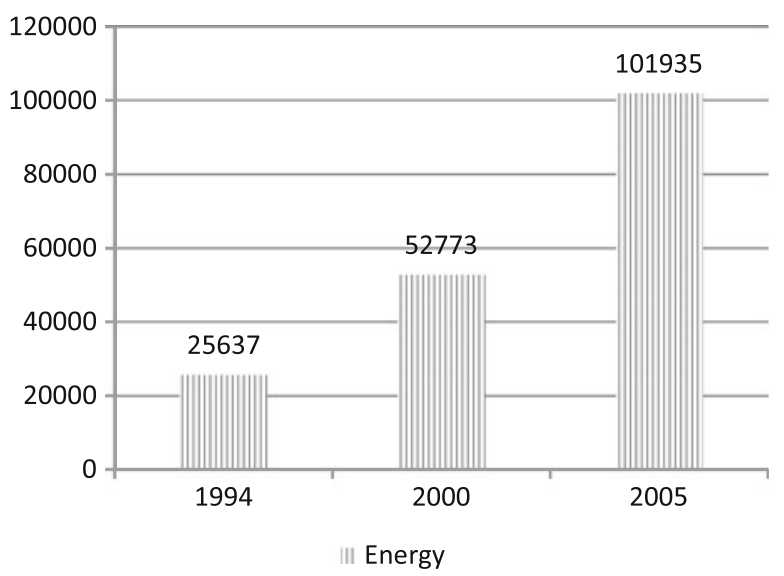

These figures suggest that in addition to contributing to the country's economic development, the increasing exploitation and use of fossil fuels (coal, oil, gas) for energy have increased GHG emissions. In the energy sector, GHG emissions come from fuel combustion, mining activities and transportation. The main types of emission inventories in the energy sector include (1) GHG emissions from fuel combustion and (2) emissions from GHG emissions. GHG emissions from fuel combustion are divided into sub-sectors: electricity, industry and construction, transportation, trade/services, civil, agriculture/forestry/fisheries, and other. Emissions from GHG emissions are due mainly to coal, oil, gas and gas leaks.

GHG inventory results in the energy sector for the years 1994, 2000 and 2005 are shown in Fig. 5.5.

In total, emissions calculated over the time inventory of GHG emissions from the combustion of fuel account for about 85-90\%, and the rest is due to leakage from the fuel extraction process (coal, oil and gas), storage and transport of fuel.

\subsubsection{Industrial Processes}

The position of industries is increasingly being confirmed in the national economy; the industries are increasingly rich and diverse, ensuring the supply of products and raw materials essential for both consumption and production. ${ }^{4}$ Export values of industrial production (in 1994 constant prices) in 2010 were estimated at 795.1 trillion VND, 4.0 times more than in 2000. In the 10 years from 2001 to 2010 the average annual increase was $14.9 \%$, while the state sector increased 2.1 times, an average annual increase of $7.8 \%$; the non-state area increased 6.5 times, an average annual increases of $20.5 \%$; regional foreign investment increased more than 4.7 times, an average annual increase of $16.7 \%$.

\footnotetext{
${ }^{4}$ Ministry of Industry and Trade 2013.
} 
A number of important industrial products for production and consumption have reached a relative high with population growth. The output of coal in 2010 reached 44.0 million tons, 3.8 times the output in 2000, an average annual increase of $13.7 \%$ over the 10 years from 2001 to $2010 ; 7.9$ million tons of rolled steel were produced, a 3.5-fold increase, with an average annual increase of $17.5 \% ; 55.8$ million tons of cement, a 3.8-fold increase, $15.4 \%$ year; 2.6 million tons of chemical fertilizers, a 2.1-fold increase, $7.8 \%$ /year; 1887.1 thousand tons of paperboard, a 4.6-fold increase, $16.5 \%$ year; 1.2 billion $\mathrm{m}^{2}$ of silk, a 3.4-fold increase, up to $13 \% / y e a r ; 436.3$ million boxes of condensed milk, a 1.9-fold increase, $6.7 \% / y e a r ; 2.4$ billion liters of beer, a 3.1-fold increase, $11.8 \% /$ year; and 91.6 billion kwh of electricity were generated, a 3.4-fold increase, $13.1 \% / y e a r$.

In addition to these results, the development of industries has exposed many shortcomings: low added value and a downward trend, with investment inefficiency and low technology levels.

GHG emissions from industrial processes are not the form of emissions related to energy use in the industrial processes. The emissions considered are those generated by the interaction of the physics and the chemistry of the material during material processing. Heavy and chemical industries in Vietnam so far are only at modest levels, so their GHG emissions are only considered as secondary sources. This is also consistent with the general trend throughout the world.

The GHG inventory for the period between 2000 and 2005 estimated emissions for different types of manufacturing industry, including cement, lime production, ammonium production, carbide production, and iron and steel production. In the first GHG inventory for 1994, the emissions also included the production of paper, alcohol and processed foods. However, the proportion of emissions from these activities is very small, so they are not included in the latter GHG inventories.

GHG inventory results for industry are shown in Fig. 5.6.

Fig. 5.6 Total GHG emissions in industrial processes in the inventory periods $\left(\times 1000 \mathrm{tCO}_{2} \mathrm{e}\right)$ (Source: Vietnam Second Communication Report 2010, and Interim Report of Inventory Capacity Building Project. JICA 2014)

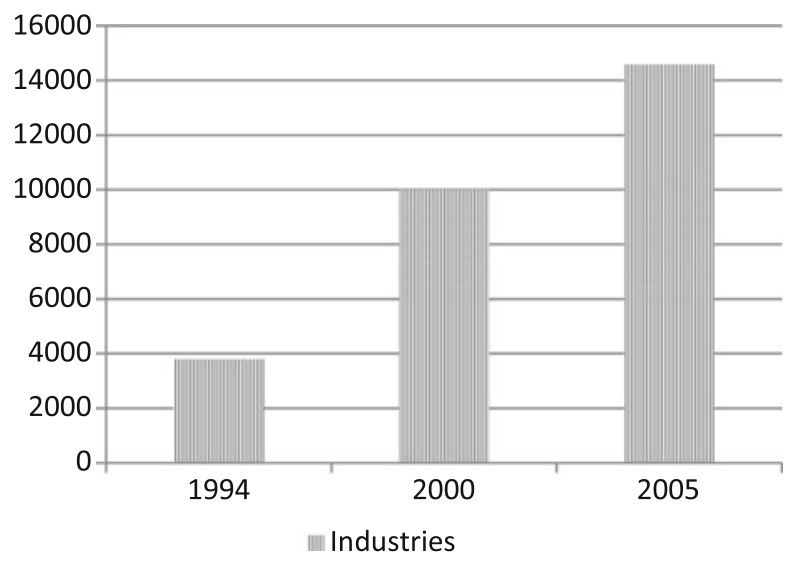




\subsubsection{The AFOLU Sector}

\section{Agriculture}

The agricultural sector in the period of 2001-2010 saw steady growth, providing products with improved quality to better meet the needs of production, domestic consumption and export. The value of agriculture, forestry and fisheries (in 1994 constant prices) in 2010 was estimated at 232.7 trillion VND, up $66.4 \%$ compared with the year 2000. The structures of agriculture, forestry and fisheries have transferred toward reducing the proportions of agriculture and forestry, with fisheries increasing in density. In 2000, the value of agricultural production (at current prices) accounted for $79 \%$ of the total output value of agriculture, forestry and fisheries, and forestry and fishing accounted for $4.7 \%$ and $16.3 \%$, respectively; by 2010 the proportions were $76.3 \%, 2.6 \%$ and $21.1 \%$, respectively. ${ }^{5}$

In addition to these achievements, the agricultural sector also has some drawbacks such as low-quality products and low value added. Development that has mainly focused on exploiting the potential of land, resources and labor rather than investment in cultivation and processing technologies has led to low-quality products. These inadequacies also lead to negative impacts of agriculture on the environment and ecology, which must be considered in terms of the increasing emissions of greenhouse gases from the types of agricultural activity.

The GHG emissions in agriculture come mainly from activities such as rice farming, raising livestock, emissions from arable land, and burning of agricultural products. The GHG emissions from agricultural activities are $\mathrm{CH}_{4}$ and $\mathrm{N}_{2} \mathrm{O}$. The agricultural activities considered in calculation of the GHG emission inventory include enteric fermentation, livestock manure management, rice cultivation, agricultural soils, and field burning of agricultural residues. Among the agricultural activities, water rice cultivation account for most GHG emissions (45-60 \%), followed by emissions from agricultural soils, enteric fermentation from cattle, and emissions from cattle manure. Other activities make up only a small proportion of emissions. Aggregate emissions from the agricultural sector are presented in Fig. 5.7

According to the 1994 GHG inventory, GHG emissions from the agricultural sector were 52.45 million tonnes of $\mathrm{CO}_{2}$ equivalents, accounting for $50.50 \%$ of total GHG emissions in the country. By the year 2000 this had changed to 65.09 million tonnes of $\mathrm{CO}_{2}$ equivalents, accounting for $43.10 \%$ of the total national GHG emissions (including emissions from rice cultivation, which accounted for $57.50 \% ; 21.85 \%$ came from agricultural soils; $11.88 \%$ came from enteric fermentation, and the rest came from manure management, and field burning of agricultural residues). According to data from the GHG inventory in 2005, GHG emissions from the agricultural sector were 83.828 million tons of $\mathrm{CO}_{2}$ equivalents, accounting for $46.10 \%$ of total GHG emissions in the country (including emissions

\footnotetext{
${ }^{5}$ General Statistic Office (2014).
} 
Fig. 5.7 Total GHG emissions from the agriculture sector $(\times 1000$ $\mathrm{tCO}_{2}$ e) (Source: Vietnam Second Communication Report 2010, and Interim Report of Inventory Capacity Building Project. JICA 2014)

Fig. 5.8 Proportion of GHG emissions from the agriculture sector in 2005 (Source: Interim Report of Inventory Capacity Building Project. JICA 2014)
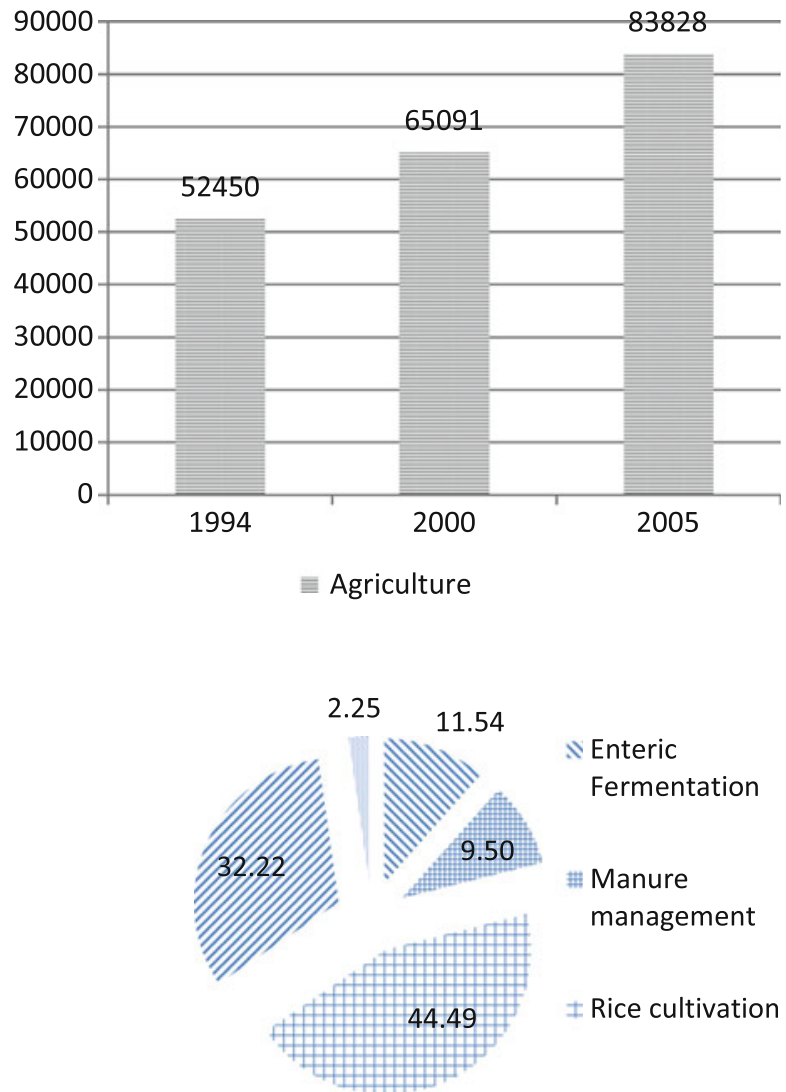

from rice cultivation, accounting for $44.49 \% ; 32.22 \%$ came from agricultural soils, $11.54 \%$ came from enteric fermentation, and the rest came from manure management and field burning of agricultural residues) (Fig. 5.8).

\section{Land Use, Land Use Change and Forestry}

Forests have roles as both emission sources and GHG sinks. Activities such as land use change and forest exploitation are the source of $\mathrm{CO}_{2}$ emissions. Meanwhile, the activities of forest protection, reforestation and afforestation are sinks. Forestry, land use and land use change are areas of great potential GHG absorption through the reservoir of carbon from forests, soil, and vegetation if they are well managed, protected and appropriately exploited. The estimation of GHG emissions and absorption in this field focuses on the following main groups of activities: changes in the reserve forest area and biomass in natural forests and plantations; conversion of land use from forest land to other land; abandoned land management; and emission and absorption of $\mathrm{CO}_{2}$ from the soil. Change of land use often causes 
Fig. 5.9 Total GHG emissions from the LULUCF sector $(\times 1000$ $\mathrm{tCO}_{2}$ e) (Source: Vietnam Second Communication Report 2010, and Interim Report of Inventory Capacity Building Project. JICA 2014)

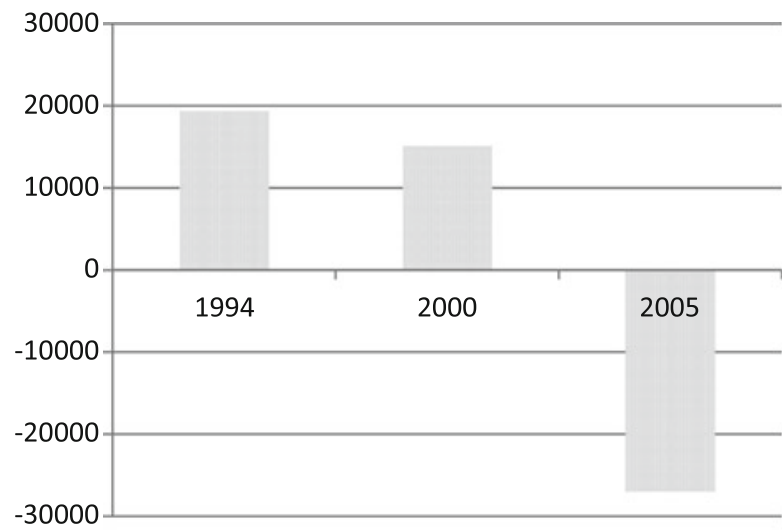

LULUCF

more $\mathrm{CO}_{2}$ emissions, while change in forest area (in term of increases) often leads to increased levels of $\mathrm{CO}_{2}$ absorption. The inventory results for this area over the inventory period are given in Fig. 5.9.

According to the 1994 GHG inventory, the amount of GHG emissions in the field of forestry and land use change was 19.38 million tons of $\mathrm{CO}_{2}$ equivalents, accounting for $18.70 \%$ of total GHG emissions in the country. The GHG inventory in 2000 estimated that the emissions in the forestry and land use change sectors was 15.10 million tons of $\mathrm{CO}_{2}$ equivalents, accounting for $10 \%$ of the total national GHG emissions. The corresponding figure in the 2005 GHG inventory was -27.02 million tons of $\mathrm{CO}_{2}$ equivalents, representing $-14.8 \%$ of total GHG emissions in the country. Thus, the LULUCF sector has become a major greenhouse gas sink in Vietnam. There is no satisfactory explanation for this sudden change in the calculated results. These issues will also need to be discussed for clarification. But it is clear that the forestry, land use and land use change sector in Vietnam has great potential for GHG absorption through the reservoir of carbon from forests, soil, and vegetation, if they are well managed, protected, and appropriately and sustainably exploited and used.

\section{Waste Management}

GHG emissions from the waste management sector are calculated for collected and disposed municipal solid wastes and GHG emissions from domestic sewage and industrial wastewater. It is estimated that every year about 15 million tons of solid waste is discharged from various sources, of which over $80 \%$ are from urban areas, and the rest is industrial waste. However, only part of this waste is collected and processed; the data show that the proportions are over $70 \%$ in urban areas and more than $20 \%$ in rural areas. 
Fig. 5.10 Total GHG emissions from the waste sector $\left(\times 1000 \mathrm{tCO}_{2} \mathrm{e}\right)$ (Source: Vietnam Second Communication Report 2010, and Interim Report of Inventory Capacity Building Project. JICA 2014)

Fig. 5.11 Proportion of GHG emissions from the waste sector in 2005 (Source: Vietnam Second Communication Report 2010, and Interim Report of Inventory Capacity Building Project. JICA 2014)

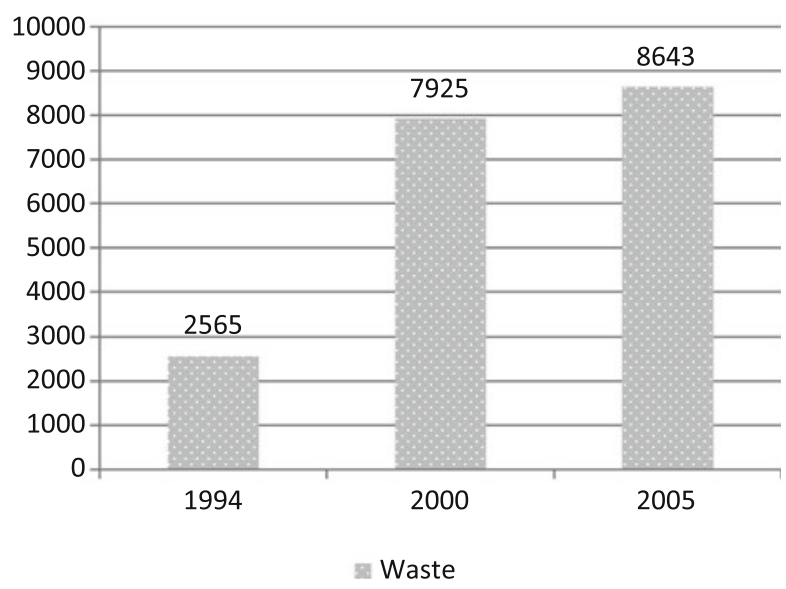

Human waste

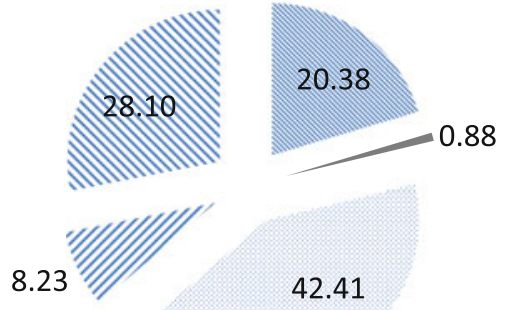

Combustion solid waste

Domestic wastewater

"Industrial wastewater

N Landfill

The calculation of GHG emissions from the waste sector in GHG inventories for Vietnam focuses on the main sources of emissions including $\mathrm{CH}_{4}$ emissions from solid waste landfills; $\mathrm{CH}_{4}$ emissions from industrial wastewater and domestic sewage; $\mathrm{N}_{2} \mathrm{O}$ emissions from domestic sewage sludge; and $\mathrm{CO}_{2}$ and $\mathrm{N}_{2} \mathrm{O}$ emissions from the incineration of waste. The inventory results are given in Figs. 5.10 and 5.11

In the waste sector, emissions from domestic wastewater are the largest, which are estimated about 3.4 million tons, accounting for about $42 \%$; the emissions from landfill waste are 2.3 million tons, accounting for $28 \%$, and the emissions from human waste are approximately 1.69 million tons. Emissions from combustion of solid waste are not high, only about $0.9 \%$ by incineration operations, as this technology is not popular. To reduce GHG emissions from the waste sector requires a focus on the areas of domestic sewage and solid waste landfill.

The data on the status of GHG emissions in Vietnam have shown that two areas that have high levels of emissions are energy and agriculture, while two other sectors, industrial processes and waste, have much lower levels. Depending on the characteristics and properties of GHG emissions in four areas, it shows that to 
reduce GHG emissions from the energy sector and industrial processes requires large investments with wide impacts on socio-economic aspects; while the potential to reduce GHG emissions from the AFOLU sector and waste management may require lower funding with fewer impacts on the economics. In particular, the LULUCF sector also has high potential for GHG absorption. However, to get a clearer view of the potential to reduce GHG emissions, it is necessary to analyze and assess the opportunities and challenges for reducing GHG emissions in Vietnam.

\subsection{Identification of External Impacts of GHG Emission Reduction Policies}

\subsubsection{Externalities of Greenhouse Gas Emission Policies}

In the context of climate change impacts, the debate about the achievements and negative impacts of policies to reduce GHGs is becoming more and more popular. Recently, this problem has attracted a more extensive and more detailed focus on the benefits and costs of the externalities of the policy options and mitigation plans. Basically, these externalities can be understood as policies and plans to reduce greenhouse gases that could, in some way, cause a positive or negative impact on the economy, public health, ecosystems, etc. And, in this case, the effects can be monetized; they should be subtracted or added to the social cost of emission reduction policies. The positive externalities can be created through minimizing damage to the environment and the health of the pollutants. Conversely, these policies can also create negative externalities for public health and the environment, for example, in the field of energy, the increased use of diesel fuel can reduce GHG emissions, but will increase the risks to environmental and human health. Generally, these externalities have not so far been studied and evaluated fully, and so rarely have been quantified in a systematic way and integrated into the emission reduction policies. Failure of consideration and evaluation of the impacts of externalities may affect the choice of policies to reduce emissions. The externality, accordingly, should be considered as one of the indicators to identify the priorities for policies to reduce GHG.

\subsubsection{The Impact of Macroeconomics}

Policy impacts on the energy sector such as fossil fuel price rises, or policies imposed on the industrial sector such as rising commodity prices related to GHG emissions, can help reduce emissions as well as the risks of climate change in the long term; conversely, however, they also reduce economic activity in many forms. 
Although these effects on the economy's growth may not be large in the long term, they need to be considered. The policies on reducing GHG emissions that impact on economic activities can be generalized as follows:

- The shift in production, investment and labor from industries related to energy production based on carbon, or products and services that use a lot of energy, to industries using alternative energy sources and consuming less energy;

- Reduced productivity of capital and labor in accordance with the cheap energy available;

- Reduced household incomes, with a reduction in domestic reserves;

- Lack of encouragement for investment due to increasing capital costs of production processes using a lot of energy;

- Reduced amount of net income from abroad (decreased productivity and increased cost of production capital), making the domestic market become less attractive to foreign investors;

- Deterioration of total labor supplies due to increases in the cost of consumer goods and reductions in the real wages of workers.

The GHG emission reduction policies may affect GDP growth through investment mechanisms. For example, high taxes on production that has a high level of GHG emissions will cause increases in production costs, thereby reducing investment and leading to a decline in product supplies and real wages. Accordingly, the consumption by people will fall and, as a result, reduce GDP. At the same time, lower wages can reduce workers' choices for employment that is unpaid or is not reflected in GDP, such as parenting, employment at home or entertaining.

\subsubsection{The Problems of Hunger Eradication and Poverty Reduction}

Solutions to reduce GHG emissions can cause a significant impact on the goal of social economic development - typically the impact of policies to reduce emissions in AFOLU on food security. The current efforts in reducing poverty, curbing malnutrition and improving incomes are oriented toward increasing the rate of food production per capita in developing countries, while population growth will require increases in income. Therefore, a policy of increasing food production is needed to ensure sustainable development of the country. Accordingly, solutions to reduce emissions from the AFOLU sector if contributing to food production will contribute positively to this work. In contrast, there will be a number of solutions that may reduce food productivity, at least at the local scale.

In the energy sector, energy scarcity has prompted developed countries to seek biofuel sources, displacing food production in agriculture. This has caused serious food shortages. These factors push up food prices, making the supply drop, and poor countries suffer the most severe consequences. 


\subsubsection{The Impact on Employment}

In the case of policy applied to goods prices based on the corresponding GHG emissions created during their production and consumption, these policies may affect the total supply as well as the distribution of employment between sectors of the economy. For example, the commercialization of emissions to manage emissions from the energy sector of the USA has only generated a small amount of change in total employment over the long term, but the changes created by this policy have partly impacted on employees. Specifically, rising energy prices reduce the real wages of workers. Meanwhile, some people may choose to work fewer hours, or even stop working to switch to operating in other areas.

Although there is no major impact in the long term, the GHG emission reduction policies can cause a significant shift in the structure of labor between sectors of the economy. For example, the commercialization of emissions from the energy sector in the USA could reduce the number of carbon- and energy-intensive industries in energy production or manufacturing of products consuming energy due to these industries facing the problems of increased production costs and reduced outputs. In particular, the energy industry, such as coal mining, oil and gas, may be most severely affected. In addition, emission reduction policies also affect employment in industries that use high-emission products, such as the transportation and chemical industries. In contrast, the policy will create new jobs in other sectors, particularly the manufacturing of machinery to produce energy without $\mathrm{CO}_{2}$ emissions, such as producing electricity from wind and solar power. Similarly, employment can be increased in sectors producing goods and services using less energy or less energy consumption products, in which the services sector may have the most significant increase.

\subsubsection{The Impact on Energy Security}

Security of the energy supply side can be defined as "the availability of energy at all times in many forms to ensure sufficient quantity and at an acceptable price" https://www.iea.org/topics/energysecurity/subtopics/whatisenergysecurity/. This definition refers to the prevention and mitigation of emergencies in the short term as well as limiting the risk of energy security in the long term.

Climate change and energy security have become the two main drivers of energy policy in the future of the country. While energy security has been the focus of energy policy for nearly a century, the concern about climate change has emerged in recent times, but has a significant influence and alters virtually all of the context of energy policy. The key problem that decision makers are faced with is how to simultaneously ensure national energy security, while reducing GHG emissions. There is no guarantee of energy security, often due to the non-availability of energy and because energy prices are not competitive or are too unstable. In fact, these 
effects are often very difficult to assess; therefore, it is difficult to determine a reasonable policy. In the context of climate change, countries usually have a certain number of activities to ensure energy security. Firstly, countries may seek to minimize the short-term effects due to lack of power supply in case of power interruption or, secondly, may make efforts to improve energy security in the long term. In the first case, the country often resolves to build strategic reserves. For example, in the case of oil, the International Energy Agency (IEA) coordinates the use of emergency oil reserves between member states. The government also seeks to establish contingency plans to limit consumption, thereby minimizing the impact due to the lack of energy. In the second case, the policies tend to focus on determination of the root causes of loss of energy security in the context of climate change, such as interruption of power systems related to catastrophes or extreme weather conditions; balancing supply and demand in the market for short-term power; monitoring the effectiveness of management and regulation; and focusing on fossil fuel sources by minimizing the possibility of the risk of depending on the supply of energy in the traditional market and reducing use of fossil fuels or diversifying the type of power supply.

Each system of energy security policy allows identification of potential overlaps with policies and measures to reduce GHG emissions from the energy sector. For example, policies to address resources can significantly affect GHG emissions and vice versa, because they tend to impact the choice of fuel and related technologies. In contrast, policies to overcome regulatory failures can only have a secondary impact on emission reduction policies. Thus GHG emission reduction policies can cause a great impact on plans and strategies to ensure energy security in the country.

\subsubsection{The Impact on the Environment}

The GHG emission reduction policies may also impact the environment. For example, in the energy sector, hydropower development can affect the environment and ecosystems at the construction site. In the AFOLU sector, emission reduction policies often affect land availability and competition, while land developers may have different perspectives on the importance of ecosystem services. Policies to increase food production may reduce environmental services. Policies to reduce GHG emissions from the agricultural sector often have positive impacts as can be seen in countries that have suffered from declines in water quality and ecology, and sedimentation. These losses can be reduced by implementing conservation tillage measures that will provide benefits in terms of land recovery, or will limit soil erosion. Other positive externalities of GHG reduction policies are changes in farming practices to cause an increase in organic matter in soil, improve the water holding capacity of the soil and reduce the need for irrigation; increased organic matter in the soil can improve soil fertility, which reduces the need to use inorganic fertilizers; conversion from farmland to grassland or forest land can improve the habitat of wildlife and biodiversity protection; restriction of fertilizer 
use can reduce the nutrient content of the overflow from agricultural land, thereby improving water quality and reducing the shortage of oxygen in rivers, streams, lakes and aquifers. These changes will improve the characteristics of the water used for non-agricultural activities in the area.

However, besides the positive impacts, the greenhouse gas emission reduction policies in the AFOLU sector can also create externalities costs that are not small, as in some cases, reducing the intensity of arable land use requires the use of more pesticides to control weeds, fungi and insects. In addition it requires additional energy for synthesis, production and application. These activities also have negative impacts on the ecosystem, flow and water quality.

\subsubsection{Reducing Costs and Losses from Climate Change Impacts}

The adoption of policies to reduce GHG emissions help to avoid the risks of climate change. Such risks include reduced potential crop yields in most tropical and subtropical regions due to the increase in temperature; reduced and changed crop yields in most regions at mid-latitudes due to the increase in average annual temperature; reduced water supplies in areas of water scarcity, especially in the subtropics; increases in the number of people exposed to vector-borne diseases (such as malaria) and water-borne diseases (such as cholera) and mortality due to heat stress (heat stress, mortality); increases in the risk of widespread flooding of many residential areas due to increased rainfall and sea level rise; and increased energy demand for cooling due to higher temperatures in the summer. The implementation of GHG reduction policies in these areas will help to avoid the costs or potential losses that are caused by climate change impacts.

\subsubsection{The Social Impact}

Social costs to operate and monitor the climate change and reduction of GHG emission programs are often not small, and include labor costs, raw materials, project implementation costs, the cost of raising awareness and compliance with emission standards, the energy accounting program, reducing emission labeling, etc. In case the costs are not included in these specific GHG emission reduction measures, they should be regarded as a form of external costs. Normally, the costs of GHG emission reduction activities are often much higher if they are calculated fully.

As the above analysis shows, to reduce GHG emissions from different sectors, in addition to calculating the direct costs for reducing emissions, there is a need to assess carefully the effects of the policy of emission reduction, especially the 
negative externalities; these are the indirect costs to be paid in reducing GHG emissions. The choices of priorities, plans and measures to reduce GHG emissions in accordance with the actual conditions of each country require consideration and full evaluation of all of the externalities.

\subsection{Selection of Priority Areas and Measures to Reduce Emissions of Greenhouse Gases}

\subsubsection{Selection of Priority Areas}

Identifying priority areas for policy implementation should be based on the criteria that the externalities have been taken into account. The implementation costs criterion represents the economic efficiency of emission reduction countermeasures, usually expressed as the monetary value per unit of $\mathrm{CO}_{2}$ avoided when implementing these measures. The assumption is that the lower the cost is, the more attractive the options are. Conversely, the choices for emission reduction measures have higher costs that will not be a priority in the early stages and can be implemented later.

The priority policies should have the ability to meet the emission reduction targets of the country. This indicator reflects the level of impact and the ability to contribute to GHG reduction targets of selected sector emission reduction measures. It is usually based on the percentage of $\mathrm{CO}_{2}$ emissions from the sector compared with the total amount of the $\mathrm{CO}_{2}$ cut off. The sectors that have higher potential emissions will be placed at greater priority.

The applicability of the policies is an important criterion to prioritize the measures. This reflects the necessity for a change in legislation or institutional systems to enable the successfully implementation of emission reduction measures. Typically, measures that require little change or effects on other policies when being implemented are often easier to implement and therefore will prevail.

There are several factors affecting the applicability and implementation of GHG emission reduction measures. If there are many similar implementing measures that have been done before, it will be better with this experience. Reducing the number of decision makers who have a key role in the implementation of measures to reduce emissions in priority areas would help to implement the measures quickly and effectively. The complexity of the preparatory activities will help to shorten the timeframe for implementation. The level of diversity of the groups that the reduction measures will be directed at should be as little as possible. As usual, a greater number of targeted groups will require more work on related policies.

The reduction measures should have the ability to combine with activities to improve the quality of life. This reflects the extent to which the measures will supplement and support policies and other measures aimed at improving the quality of life of people, such as poverty reduction and energy security. To a certain extent, 
this reflects the priority that reducing emissions will not only limit the amount of $\mathrm{CO}_{2}$ emissions but also contribute to reducing the burden of negative effects on people's health or the ecosystem.

Preferable measures will help to create job opportunities. This is the social impact of the measures. It is mainly based on indicators of jobs directly created to implement measures in priority areas to reduce emissions.

Another important factor to be considered in determining the priority areas for reducing $\mathrm{GHG}$ emissions is that they need to be in compliance with the priorities of the country's development policies. Determining priority areas for GHG emission reduction therefore is weighted in accordance with the development goals of the country. The priorities for development will be essential in determining areas for reducing GHG emissions.

\subsubsection{Identifying Technical Solutions-Technology Priorities in Reducing Greenhouse Gas Emissions}

After defining the field of emissions and identifying technical solutions, specific technologies to reduce emissions from different sectors also have very important implications for the GHG emission reduction strategy of the country. Usually, technical solutions and technologies are applied to the sector, and sub-sector emission reduction priorities are classified according to their applicability in the short term and long term, or on a large or small scale. The classification results allow comparison with other solutions and building system solutions applied over time. Accordingly, the solution can be applied to many sectors/sub-sectors, though not with the highest priority in all sectors/sub-sectors identified.

\subsubsection{Lessons for Vietnam}

The identification of priority areas to reduce emissions requires specific research, based on national conditions and the development goals. Accordingly, there is a need to develop criteria to identify areas in which to consider the full range of aspects of the potential to reduce emissions, the ability to deploy, the cost and other economic, social and environmental effects.

For reduction of GHG emissions from the energy sector and the promotion and development of new energy sources, renewable energy often requires great support financially from the government to businesses, including investment costs, installation costs, operating costs and R\&D activities. Therefore, for developing countries like Vietnam, the budget must also cater for multiple items for other urgent development, and focusing on investment in the development of renewable energy sources will encounter many difficulties, so there is a need for a strategy and 
roadmap for this. As an agricultural country, Vietnam has the potential for development of bioenergy from agricultural by-products to partially replace fossil fuels to reduce GHG emissions without too much investment cost.

With the economy still relying heavily on agriculture in the next decade, not only for rice but also for other industrial crops (coffee, tobacco, rubber, pepper, and cashews), Vietnam needs to focus on building sustainable agriculture and application of advanced agricultural technologies to maintain and develop the quality and quantity of agricultural production in the context of climate change. For application of this new technology, besides support from the Government of Vietnam, support from developed countries should be enlisted in parallel with relief efforts. This will ensure appropriate orientation and mitigation of GHG emissions associated with climate change adaptation under the most favorable orientation for Vietnam.

In the forestry sector, the strengthening of forestry on vacant land in the tropics is known as an effective measure to reduce $\mathrm{CO}_{2}$, the main GHG in the atmosphere. In addition to reforestation efforts and reforestation on barren hills, recently the international community has also shown interest in sustainable management of the available forest resources. REDD+ initiatives have been proposed and have received the attention of many nations. This initiative stems from the fact that deforestation and forest degradation contribute a large proportion (15-20\%) of the total amount of GHG emissions due to human activities, and the cause is global in scope.

The formulation and implementation of policies to reduce GHG emissions need to be considered in a comprehensive manner, which requires close coordination between ministries and departments.

The GHG emission reduction strategies should be implemented in a flexible manner, combining policy commands with incentives and economic and technical support to encourage the cooperation of the relevant parties.

Efforts should be made to encourage participation and promote the role of stakeholders in the GHG emission reduction activities. The involvement of the community and stakeholders not only helps to ensure cooperation with and support of government policies but also can help to sustain the motivation of the Government in working toward GHG emission reduction targets.

Leverage, promoting investment, is an important factor in GHG mitigation and response to climate change, especially in developing countries with limited funds. The collaboration and support between Norway and Brazil in the successful campaign to reduce emissions from deforestation in Brazil have demonstrated the role and importance of external sources of support for activities to reduce emissions.

Application of techniques and technology is one of the essential elements to ensure effective policies and activities to reduce emissions, and in return, such mechanisms and policies are promoting the implementation and application of technical solutions and technologies to reduce GHG emission practices.

Open Access This chapter is distributed under the terms of the Creative Commons Attribution Noncommercial License, which permits any noncommercial use, distribution, and reproduction in any medium, provided the original author(s) and source are credited. 


\section{References}

Decision 1393/QĐ-TTg dated 25/09/2012. "Chiến lược Tăng trưởng xanh quốc gia" (2012, in Vietnamese). Available at: http://vanban.chinhphu.vn/portal/page/portal/chinhphu/ hethongvanban?_page $=1 \&$ class_id $=2 \&$ document_id $=163886 \&$ mode $=$ detail

General Statistic Office (2014) Yearly Statistics Publication

JICA Inventory Capacity Building Project (2014) Interim report, June 2014. Ministry of Natural Resources and Environment of Vietnam

Low-Emission Development Strategies (LEDS), Technical, Institutional and Policy Lessons. Clapp et al. OECD (2010); Available at http://www.oecd-ilibrary.org/environment/low-emis sion-development-strategies-leds_5k451mzrnt37-en?crawler $=$ true

Ministry of Industry and Trade (2013) Situation and development direction of environmental technology of Vietnam up to 2020, vision 2030. In: Conference of environmental technology development, 2013, Ministry of Trade and Industry of Vietnam (in Vietnamese)

The Second Communication Report, Ministry of Natural Resources and Environment (MONRE), 2010

UN Data. http://data.un.org/Data.aspx?d=MDG\&f=seriesRowID:751 